\title{
O Banco Mundial e a política científica dos governos militares no Brasil
}

Mônica Dias Martins

Ao longo de décadas, a ingerência do Banco Mundial alastrou-se por quase todos os domínios da atividade pública brasileira. Este artigo trata especificamente das orientações desta agência multilateral para o desenvolvimento científico e tecnológico durante a ditadura militar, destacando a montagem do Sistema Nacional de Desenvolvimento Científico e Tecnológico (SNDCT) e a implantação do Programa de Apoio ao Desenvolvimento Científico e Tecnológico (PADCT).

Palavras-chave: Governos Militares, Desenvolvimento Científico, Banco Mundial, Brasil.

\section{Mônica Dias Martins:}

Professora do Mestrado

Acadêmico em Políticas Públicas

e Sociedade da Universidade

Estadual do Ceará, coordenadora

do Observatório das

Nacionalidades.

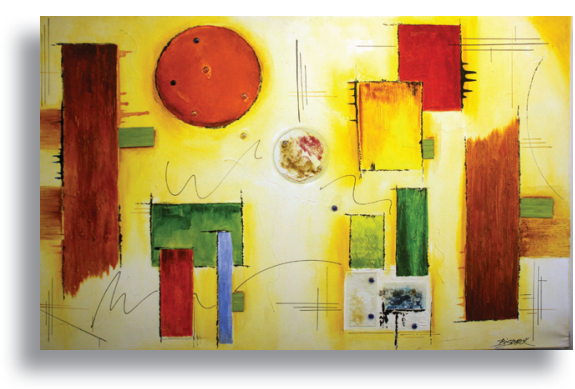

\section{World Bank and scientific policy of the military governments in Brazil}

For decades, the intervention of the World Bank has spread to almost all areas of public life in Brazil. This article deals specifically with the guidelines of the multilateral agency for scientific and technological development during the military dictatorship, especially the assembly the National System of Scientific and Technological Development (SNDCT) and the implementation of the Program of Support for Scientific and Technological Development (PADCT).

Key words: Military Governments, Scientific Development, World Bank, Brazil. 


\section{INTRODUÇÃO ${ }^{1}$}

As orientações do Banco Mundial para a ciência e a tecnologia no período da ditadura militar no Brasil constituem o objeto do presente artigo. Após o golpe de 1964, a ingerência deste organismo multilateral alastrou-se por quase todos os domínios da atividade pública.

Expressivas mudanças na política de ciência e tecnologia ocorreram em 1975, com a montagem do Sistema Nacional de Desenvolvimento Científico e Tecnológico (SNDCT), e em 1984, com o aporte de recursos internacionais para implantar o Programa de Apoio ao Desenvolvimento Científico e Tecnológico (PADCT). Acompanhando as diretrizes do Banco Mundial, os militares empreenderam a "modernização" do Conselho Nacional de Desenvolvimento Científico e Tecnológico (CNPq), que ganhou novo formato e atribuições, adotou o planejamento plurianual e a classificação das áreas de conhecimento, instituiu a avaliação de mérito por pares e um sistema de cadastro e informação. Chama atenção a capacidade de, em meio à coerção massiva e à preleção nacionalista, o Banco Mundial lograr influir nas decisões de um setor estratégico para projeção da soberania do Brasil.

Inicialmente, apresento algumas ideias do Banco Mundial sobre o desenvolvimento científico e um breve histórico da sua atuação no Brasil, no intuito de melhor compreender o sentido das reformas na política científica empreendidas pelo regime militar. As visitas ao Centro de Memória do CNPq possibilitaram colher material para examinar os acordos entre o Banco Mundial e essa agência de fomento, notadamente as atas das reuniões do Conselho Científico e Tecnológico (CCT). No Instituto de Pesquisa Econômica Aplicada (IPEA), depositário do acervo bibliográfico do Banco, consultei os "Relatórios de Desenvolvimento Mundial", entre outros documentos, e contatei a Ouvidoria em busca de esclarecimentos acerca das relações do Estado brasileiro com o Banco Mundial. ${ }^{2}$

\footnotetext{
1 Este trabalho integrou o projeto de pesquisa "O militar e a ciência no Brasil", apoiado pelo CNPq e coordenado por Manuel Domingos Neto (UFF). Versões preliminares foram apresentadas no II Enabed (2008), no XIV Congresso da SBS e no Seminário na Escola de Guerra Naval, ambos em 2009.

2 Agradeço aos funcionários do CNPq e do IPEA pela ajuda na identificação e no acesso a importantes documentos.
} 


\section{O BANCO MUNDIAL E O DESENVOLVIMENTO CIENTÍFICO}

O Grupo Banco Mundial designa um complexo formado por instituições, criadas ao longo das últimas seis décadas, com diferentes atribuições: Banco Internacional de Reconstrução e Desenvolvimento (BIRD) (1944), Corporação Financeira Internacional (CFI) (1956), Associação Internacional de Desenvolvimento(AID) (1960), Centro Internacional para Arbitragem de Disputas sobre Investimentos (CIADI) (1966), e Agência Multilateral de Garantia de Investimentos (AMGI) (1988). Hoje, com 187 Estados-membro, o Banco Mundial presta assistência técnica e financeira a mais de 100 países, na condição de serem estes também integrantes do Fundo Monetário Internacional (FMI). A instância deliberativa máxima destas duas entidades é o Conselho de Governadores, sendo o voto proporcional à contribuição monetária de cada país (cota-parte do capital subscrito). Na qualidade de maior acionista (15,85\%, em 2010), os Estados Unidos têm prerrogativa de veto e nomeiam o presidente do Banco Mundial, enquanto os sócios europeus indicam o diretor-gerente do FMI. $^{3}$ Admitido como expressão máxima do multilateralismo, de fato, o Banco constitui um instrumento auxiliar da política externa estadunidense; suas concepções de desenvolvimento relacionam-se estreitamente às tendências guerreiras e aos interesses expansionistas da potência ocidental hegemônica (MARTINS, 2007).

Este organismo multilateral se firmou rapidamente como influente produtor de conhecimentos e difundiu a ideia de desenvolvimento baseada na industrialização, mediante a transferência de capitais e tecnologias das sociedades "modernas" para as "tradicionais". Com a derrota dos EUA no Vietnã, o Banco Mundial passou a arregimentar nas universidades seus quadros técnicos, anteriormente recrutados entre os estrategistas militares do Pentágono. ${ }^{4} \mathrm{O}$ paradigma de desenvolvimento elaborado por profissionais de formação keynesiana e defensores do planejamento estatal exigiu um trabalho sistemático de difusão de valores e padrões modernos, aliado a empréstimos vultosos e grandes obras de infraestrutura. No ponto de vista do Banco, a "ajuda internacional" constituiria o único caminho para "combater"

3 Desde $1^{\circ}$ de julho de 2007, Robert Zoelick, que foi diretor da Goldman Sachs e representante dos Estados Unidos na Organização Mundial do Comércio, ocupa o cargo de $11^{\circ}$ presidente do Grupo Banco Mundial.

4 O recrutamento e a formação de quadros do Banco Mundial encontram-se detalhados em Martins (2006, p.74). 
a pobreza, sua principal missão e fonte de prestígio intelectual e de legitimidade política. ${ }^{5}$

A definição de desenvolvimento com a qual o Banco Mundial operava, em meados da década de 1970, era "aplicação de tecnologias produtivas e de gestão". Segundo publicação sob os auspícios do próprio Banco, intitulada Clés pour le transfert technologique (GONOD, 1974), os países passariam por estágios tecnológicos até se tornarem conscientes da necessidade de políticas e instrumentos que permitiriam absorver tecnologia importada sem ferir interesses nacionais. Essa proposição alimentava expectativas nas sociedades "atrasadas" de que um continuado processo de transferência tecnológica seria capaz de promover melhorias na produção e na gestão dos serviços de educação, saúde, transporte, etc.

Algumas orientações específicas sobre o papel da ciência no desenvolvimento podem ser inferidas do primeiro "Relatório do desenvolvimento mundial" (1978), embora ainda não estivessem apresentadas de forma sistemática e explícita, como acontece na atualidade. ${ }^{6}$ Delas, a mais destacada e persistente era a de que uma inversão eficiente de capital exigiria, "como tarefa inicial do desenvolvimento", a formação de uma classe empresarial "dinâmica" e de instituições públicas "estabelecidas" para executar projetos produtivos (1978, p. 7). Tal diretriz implicava a capacitação de quadros burocráticos especializados na elaboração de diagnósticos que fundamentassem o planejamento e a gestão da atividade científica, em conformidade com o pensamento do Banco Mundial.

Após identificar deficiências no campo da investigação agrícola, defasagem da evolução tecnológica industrial relativamente à intensidade de mão de obra e problemas tecnológicos decorrentes da falta ou má qualidade dos serviços públicos, o relatório propunha a expansão da capacidade nacional de gerar técnicas agropecuárias adaptadas às condições edafoclimáticas locais (1978, p. 5), o estabelecimento de vínculos "adequados" para transferir tecnologias e manter canais "abertos" de comercialização de modo a ampliar as exportações de manufaturados (Ibid., p. 33) e, finalmente, a adoção de

5 Para uma discussão sobre o conceito de pobreza do Banco Mundial, ver Martins e Farias (2007).

6 Acerca das orientações atuais, ver Innovation Systems: World Bank support of science and technology development (2004) e Science, technology and innovation: capacity building for sustainable and poverty reduction (2008). Em 1996, o Banco Mundial promove um workshop sobre política científica e tecnológica no Brasil. O relatório Institutional and entrepreneurial leadership in the Brazilian science and technology sector: setting a new agenda (1996) apresenta estratégias para aumentar a eficiência dos investimentos em ciência e tecnologia. 
tecnologias que possibilitassem o acesso da população aos serviços públicos a "baixo custo" (Ibid., p. 40).

Em síntese, as orientações para o desenvolvimento científico e tecnológico veiculadas pelo Banco Mundial, nos anos 1970 e 1980, tinham como premissa o efeito "benéfico" da transferência sistemática de conhecimentos e inovações produzidos nos centros avançados. Ao Estado do país "beneficiário" caberia facilitar este processo, assegurando políticas e instituições públicas consolidadas, além de financiamento à pesquisa.

\section{O BANCO MUNDIAL NO BRASIL}

O Banco Mundial começou a atuar no Brasil em 1949, quando da visita do presidente Eurico Gaspar Dutra aos Estados Unidos. Contudo, os dois países apresentavam expectativas distintas quanto à forma de colaboração econômica para o desenvolvimento. Enquanto o governo brasileiro pretendia garantir algo similar ao Plano Marshall (1948-1952) para a Europa, o governo estadunidense preferia tratar as questões do desenvolvimento no âmbito do BIRD. No auge da Guerra Fria, os empréstimos, antes voltados à recuperação dos países destruídos pela Segunda Guerra, foram destinados às nações do bloco capitalista.

A nova postura do Banco Mundial repercutiu no planejamento da economia brasileira. Um aspecto-chave para a legitimidade do projeto nacional-desenvolvimentista, que se estende da eleição de Getúlio Vargas (1951-1954) a meados da década de 1960, foi a ênfase na noção de soberania: o desenvolvimento fortaleceria a capacidade de autodeterminação nacional, assentada nas riquezas naturais e na afirmação da "grandeza" do Brasil perante a comunidade internacional.

De Vargas a Jango, os fundamentos do discurso nacionalista, em suas diferentes nuances, acompanhavam as tendências da hierarquia militar, mobilizavam setores do movimento dos trabalhadores, sensibilizavam as esquerdas, mas não deixavam de justificar a "ajuda" externa. Longe de arranhar a soberania nacional, a cooperação internacional para o desenvolvimento era percebida pelos governantes brasileiros como favorável à organização de um sistema de segurança do continente americano, à defesa da democracia ameaçada pela pobreza e à redução do atraso científico-tecnológico.

No tocante à produção do conhecimento científico, predominavam o distanciamento entre a pesquisa básica e o sistema produtivo, o elitismo na formação profissional e a precariedade dos investimentos em 
tecnologia. Ademais, os vínculos do Estado com as poucas associações científicas existentes à época eram limitados em virtude da ausência de uma instituição pública que servisse de referência e exercesse coordenação efetiva sobre a incipiente comunidade acadêmica. ${ }^{7}$

Nesse âmbito, a institucionalização da pesquisa científica como parte da política nacional de desenvolvimento, uma sugestão da ONU aos países-membro, resultou do entusiasmo de governantes, militares e cientistas pelo domínio de conhecimentos sobre a energia atômica. Representante do Brasil na Comissão de Energia Atômica do Conselho de Segurança, o almirante Álvaro Alberto foi o primeiro presidente do CNPq (1951). ${ }^{8}$ Sua demissão, alavancada por defensores da cooperação unilateral com os EUA, coincidiu com o enfraquecimento das funções estratégicas do órgão, até então encarregado do programa nuclear, notadamente quanto à capacitação de recursos humanos.

Ao longo do período nacional-desenvolvimentista, as ações do BIRD eram restritas a projetos de investimento nos setores de energia e transportes. O primeiro empréstimo aprovado, em 1949, destinava-se à Brazilian Light \& Power Company. De acordo com diretrizes emanadas do organismo internacional, a ampliação da capacidade de infra-estrutura produtiva necessária à expansão dos capitais internacionais constituía pressuposto básico para a modernização industrial dos países "subdesenvolvidos", em particular para a emergência da indústria de bens duráveis de consumo (GONZALEZ et al., 1990, p. 150).

Embora houvesse sintonia entre o Banco Mundial e o governo brasileiro quanto às prioridades de financiamento para a industrialização, sendo a agricultura relegada a segundo plano, as divergências na condução da política econômica evidenciaram-se desde o segundo mandado de Vargas, com a implantação de medidas restritivas ao capital estrangeiro. A "instabilidade política" e a "desordem social" foram os argumentos formais do BIRD para suspensão, em junho de 1959, dos empréstimos aos governos de Juscelino Kubitschek (1955-1960), Jânio Quadros (janeiro a agosto de 1961) e João Goulart (1961-1964).

De fato, o rompimento ocorreu quando a crescente pressão das instituições internacionais para ajustar a economia de acordo com seus padrões se tornou incompatível com as pretensões do Brasil de acele-

7 As principais entidades representativas da comunidade científica no Brasil, em meados do século XX, eram a Associação Brasileira de Ciências(ABC) (1921) e a Sociedade Brasileira para o Progresso da Ciência (SBPC) (1948).

8 Para mais informações sobre a criação do CNPq, consultar Andrade (2010). 
rar o crescimento. Iniciativas vitais para a integração nacional, como a construção de Brasília e a criação da Sudene, geraram controvérsias entre o Estado brasileiro e os organismos multilaterais em atuação no país. Consoante, o slogan "Cinquenta anos em cinco", o governo JK rejeitou os mecanismos ortodoxos antiinflacionários preconizados pelo BIRD/FMI e adotou um plano de estabilização da moeda favorável à expansão econômica (CARDOSO, 1978).

"Instabilidade e desordem" foram consideradas por Juscelino como problemas passageiros e inerentes à própria dinâmica do desenvolvimento, não pondo em risco nem o regime democrático nem o capital estrangeiro. Em plena crise de relacionamento com as instituições multilaterais, apesar da inflação acentuada, das greves e tentativas de golpe, o presidente advertiu:

Relativamente aos resultados alcançados, os efeitos da revolução econômica em curso neste país não têm sido tão graves quanto o quereriam os inimigos do Brasil grande, os inimigos do Brasil forte, os inimigos do Brasil independente, inimigos por falta de visão e inimigos por interesses contrariados (CARDOSO, 1978, p. 485).

No inerente às relações exteriores, o Brasil ansiava por maior participação nas decisões globais e empunhava a bandeira do desenvolvimento latino-americano e da defesa do "mundo livre", em um momento no qual a hegemonia estadunidense no continente se sentia ameaçada pela revolução cubana. Com base nas premissas de que o crescimento econômico seria indissociável da segurança coletiva e o fim da miséria evitaria a presença de ideologias "estranhas", proposições como a Operação Pan-Americana (OPA) (1958) e o BID (1960) encontraram ressonância na Organização dos Estados Americanos/OEA (CERVO; BUENO, 2008). Ao discursar na Escola Superior de Guerra (ESG), em 26/11/1958, Juscelino assinalou: "O significado da OPA transcende de muito os limites da política continental e vem ajustar-se às novas modalidades da crise mundial, num momento crítico para o Ocidente" (CARDOSO, 1978). Enquanto a proposta brasileira permaneceu no âmbito das intenções, a dos EUA se concretizou: o BID, organismo regional de desenvolvimento, formado por vinte países, seguiu o padrão do Banco Mundial.

Assumindo conduta "independente" na política externa, os governos Jânio e Jango ampliaram os contatos com o mundo socialista e os novos Estados que emergiam das guerras de independência nacional na África e Ásia manifestaram apoio à luta contra o subdesenvolvimento e o colonialismo, defenderam a autodeterminação dos povos e a cooperação com os países latino-americanos, renegociaram a dívida com credores 
internacionais e, ainda, acataram promessas de ajuda do FMI e da AID, entidade integrante do Grupo Banco Mundial. Apesar das pressões estadunidenses, a tendência da diplomacia brasileira era de não alinhamento automático e isto se exprimia nas posições do país perante os organismos multilaterais.

Logo após o golpe de 1964, a aproximação entre o Banco Mundial e os governos militares garantiu financiamentos contínuos e direcionados para fortalecer o modelo de desenvolvimento associado ao capital internacional (GRÁFICO 1). Ao tempo em que a ditadura reprimia movimentos sociais, dissolvia partidos políticos, acionava mecanismos de persuasão e propaganda, múltiplas iniciativas eram inspiradas e monitoradas por um organismo multilateral. Sucessivas missões do BIRD negociaram com os militares as condições para empréstimos, diagnosticaram problemas e propuseram soluções, além de formular diretrizes e metodologias para as políticas públicas.

\section{Gráfico 1. Brassili Gastos do Banco Mundial}

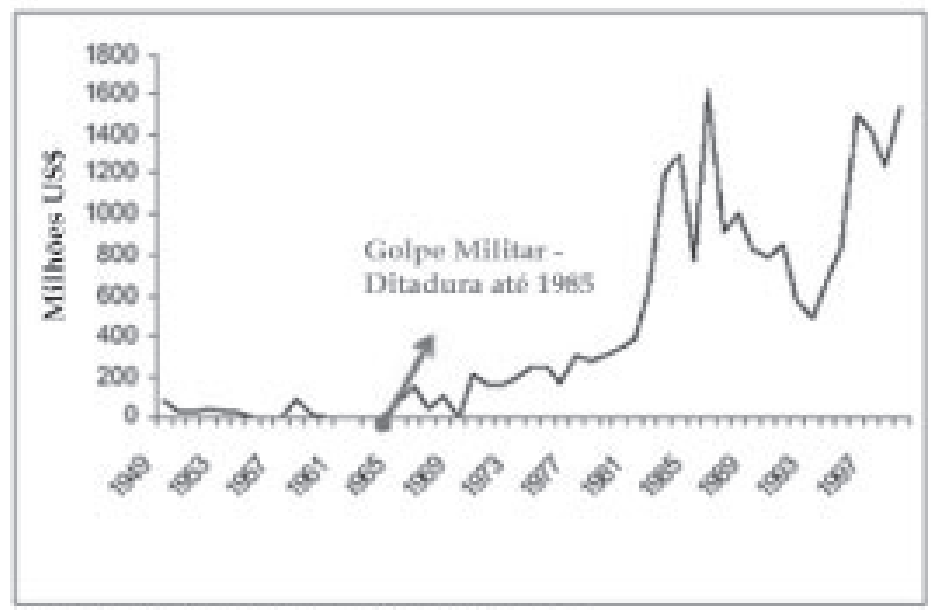

Fontes Banco Mundial CD-Rom GDF, 2001

Nesse âmbito, os generais acompanharam as formulações do Banco Mundial, que dirigido por Robert McNamara (1968-1981) difundia que a segurança de uma nação dependeria do seu desenvolvimento. ${ }^{9}$ Esta ideia era familiar aos oficiais brasileiros, sendo disseminada no processo de modernização do Exército ao longo da Primeira República (DOMINGOS NETO, 2004), e passou a orientar a ditadura. A doutrina de segurança

9 Para mais aprofundamento desta concepção, ver McNamara (1968). 
nacional irradiada a partir da ESG adotou o binômio "segurança e desenvolvimento". Na ótica dos golpistas, apenas as mudanças conduzidas pelo regime militar evitariam o que consideravam como "desordem social e instabilidade política". Assim, buscavam interromper o movimento em favor de reformas estruturais, o qual, iniciado nos anos 1950, ganhou amplitude na gestão de Goulart. Nas palavras do presidente Ernesto Geisel (1974-1979), caberia ao Estado construir a "nação":

A nação não se desenvolve espontaneamente. É preciso alguém que a oriente e a impulsione, e esse papel cabe ao governo. Esta é uma idéia antiga que possuo, sedimentada ao longo dos anos de vida e esposada nos cursos da Escola Superior de Guerra (CASTRO; D'ARAÚJO, 1997, p. 287).

Com efeito, o governo militar estruturou um colossal setor público: centralizou antigas agências setoriais e regionais; criou empresas estatais de pesquisa, planejamento, habitação, energia, telecomunicação; definiu áreas e programas prioritários no setor de ciência e tecnologia; incentivou atividades culturais e desportivas; ampliou o sistema de ações integradas de saúde e educação; estendeu os benefícios da previdência social aos trabalhadores do campo. Com empréstimos do BIRD, até então sem precedentes tratando-se do meio rural, instituiu programas especiais para o Nordeste, a Amazônia e o Centro-Oeste, os chamados "Polos de desenvolvimento integrado", e implantou projetos hidrelétricos, agropecuários, industriais, de irrigação e colonização que modificaram as relações de produção, sem, no entanto, alterar a concentração fundiária, a distribuição da renda e as condições de vida no campo.

Como exposto, a ofensiva modernizadora dos generais converteu o Brasil em um país integrado, industrial e urbano, acentuando as desigualdades sociais e a dependência do estrangeiro. O Banco Mundial contribuiu decisivamente com este processo e fortaleceu a imagem do regime junto à opinião pública nacional e internacional. A "assistência técnico-financeira" era bem acatada, até mesmo por opositores da ditadura, amparados no discurso de "participação", ou seja, no envolvimento da população "beneficiária" nas ações governamentais. Quando da construção da barragem de Itaparica, por exemplo, o Banco chegou a ser visto como aliado dos movimentos sociais, mais especificamente do Polo Sindical do Submédio São Francisco, apesar de cerca de 50 mil pessoas serem desalojadas, em Pernambuco e na Bahia, para construção de uma usina hidrelétrica (19791988) com capacidade para gerar 1 milhão e 480 mil kW e armazenar 10,7 bilhões de $\mathrm{m}^{3}$ de água. ${ }^{10}$

10 CHESF, Grupo Executivo de Reassentamento da População de Itaparica, Outubro 1997. www.mincetur.gov.pe/vilcanota/pdfs/5_Conflitos/5_1_RESOLUAOO_Osvaldo.pdf 
Entretanto, os militares não mantiveram um alinhamento incondicionale, porvezes, divergiram do Banco Mundial, notadamente quanto às proposições voltadas para o meio ambiente e a produção de energia. Por ocasião da primeira "Conferência das Nações Unidas sobre desenvolvimento e meio ambiente", realizada em Estocolmo, no ano de 1972, o Brasil defendeu a proposta secundada pelo grupo dos não alinhados de que as nações pobres não poderiam sacrificar o crescimento econômico nem preterir o uso das suas riquezas naturais em nome do controle populacional e da poluição.Conforme exposto por Viola e Leis (1990), o Brasil liderou 77 países em desenvolvimento, entre 113 participantes, que perceberam no "ambientalismo" dos países industrializados uma estratégia para garantir a ampliação do seu domínio. Em consequência, a declaração final incluiu itens voltados a resguardar a soberania das nações sobre seus territórios e recursos naturais como condição para alcançar o desenvolvimento. De acordo com os argumentos do representante brasileiro, os problemas ambientais não decorriam da explosão demográfica, mas do excesso de produção e consumo nos países ricos.

No governo Geisel, as relações com o Banco Mundial ficaram particularmente tensionadas em decorrência do Acordo Nuclear assinado com a Alemanha para construção de três usinas e implantação do Programa Nacional do Álcool (Proálcool). No caso da fabricação e do uso do álcool carburante, os militares retomavam o incentivo governamental ao setor canavieiro, inclusive para o desenvolvimento de pesquisas agronômicas e a difusão de tecnologias, que datavam de 1931 e tiveram significativo impulso durante a Segunda Guerra (Szmrecsányi, 1979). Apesar de posteriores repercussões ambientais e sociais negativas, estes empreendimentos sinalizavam a afirmação de um projeto nacional estratégico para produzir energia e garantir a autossuficiência do país (MARTINS, 2008).

Constrangido pela inflação, por variados escândalos de corrupção e pelo crescente movimento em favor da redemocratização, o último governo militar atendeu às exigências do Banco Mundial relacionadas à liberalização da economia. Este intencionava disciplinar a ação do Estado, em particular das empresas públicas, cuja "ineficiência" contrastaria com o desempenho "eficaz" do setor privado. Nesse intuito, passou a valorizar o "planejamento participativo" e as organizações da sociedade civil, o que lhe permitiria, com a volta dos civis ao exercício do poder, manter sua ingerência na definição e hierarquização dos grandes objetivos 
nacionais, das políticas macroeconômicas, das prioridades sociais e setoriais, das fontes de recurso orçamentário. ${ }^{11}$

\section{A MONTAGEM DO SISTEMA NACIONAL DE CIÊNCIA E TECNOLOGIA}

Por iniciativa do governo Castello Branco foi constituído o Fundo de Desenvolvimento Técnico-Científico junto ao Banco Nacional de Desenvolvimento (BNDE) e alterada a lei de criação do CNPq, que passou a deter competência de conduzir a política científico-tecnológica. Nos anos seguintes, a ditadura ampliou o aparato institucional de fomento à pesquisa, com a estruturação da Financiadora de Estudos e Projetos (FINEP) (1967). Com tais medidas objetivava integrar as ações de ciência e tecnologia à estratégia global de crescimento econômico.

A cada Plano Nacional de Desenvolvimento (PND) correspondeu um Plano Básico de Desenvolvimento Científico e Tecnológico (PBDCT). "Trata-se não de um programa setorial [...] mas de uma força motora. É o conduto por excelência da idéia de modernização, essencial à consolidação de uma economia poderosa e competitiva", asseverava o então ministro do Planejamento, João Paulo dos Reis Velloso, na exposição de motivos do decreto de aprovação do PBDCT encaminhada ao general Médici (1970-1973). ${ }^{12}$

Tendo em vista a afirmação do Brasil como potência, o II PND (1975-1979) enfatizou os avanços tecnológicos e a inversão em usinas, hidrelétricas e siderurgias, por meio de estímulos do Estado à empresa privada nacional, à pesquisa aplicada e à absorção de tecnologia importada. Na ótica de José Dion de Mello Teles, presidente do CNPq neste período, embora congregasse os melhores quadros da pesquisa básica no país, a agência era uma autarquia federal típica, uma estrutura "enrijecida e formal", incapaz de cumprir a função de moderno instrumento necessário para desenvolver o país (Motoyama, 2002, p. 262).

Em 1975, o CNPq passou a coordenar o sistema de ciência e tecnologia, com sua transformação em Conselho Nacional de Desenvolvimento Científico e Tecnológico, a implantação do SNDCT e a elaboração do II

\footnotetext{
11 Essa nova metodologia de planejamento e controle do Banco Mundial, denominada "Estratégia de Assistência ao País", foi implantada no Brasil a partir de 1990.

12 PBDCT. Plano Básico de Desenvolvimento Científico e Tecnológico 1973/74. Presidência da República, junho de 1973, p. VII. Reis Velloso teve papel destacado nas negociações que possibilitaram o retorno de diversos cientistas ao Brasil (FREIRE JR; SANTANA, 2010, p. 157-159).
} 
PBDCT. A fundação, que se transferiu do Rio de Janeiro para Brasília, adquiriu autonomia administrativo-financeira, de modo a facilitar a importação de equipamentos e materiais necessários à pesquisa, e experimentou outra dinâmica institucional, mediante sua vinculação à Seplan, juntamente com o IPEA, o BNDE e o IBGE. Foram incorporadas ao CNPq duas organizações pioneiras no campo do conhecimento: o Observatório Nacional (ON) (1827), que até 1976 se encontrava ligado ao Ministério da Educação e Cultura (MEC), e o Centro Brasileiro de Pesquisas Físicas (CBPF) (1949).

A segmentação das áreas do conhecimento e a padronização de termos e instrumentos eram consideradas medidas imprescindíveis para assegurar a competitividade internacional da produção científica brasileira e o exercício da coordenação do SNDCT pelo CNPq. As instituições a ele subordinados - Instituto de Matemática Pura e Aplicada (IMPA) (1951), Instituto Nacional de Pesquisas da Amazônia (INPA) (1952), o Instituto Brasileiro de Informação em Ciência e Tecnologia (IBICT) (1954) e o Instituto de Pesquisas Espaciais (INPE) (1971) - realizaram levantamento das atividades científicas sob sua responsabilidade e o enquadramento dos profissionais na carreira de pesquisador. Conforme a primeira tabela de classificação das áreas do conhecimento (1976) adotada pelo CNPq, houve relativa expansão do campo das humanidades, doravante coberto com recursos para pesquisas sociais e capacitação de quadros profissionais.

No tocante ao gerenciamento dos incentivos à pesquisa, a principal mudança no CNPq deveu-se ao estabelecimento da avaliação de mérito efetivada por meio de comitês assessores organizados por área do conhecimento. A classificação dessas áreas procurou acompanhar as proposições do "Manual de Frascati", cuja primeira versão foi publicada em 1963, por iniciativa da Organização para a Cooperação e o Desenvolvimento Econômico (OCDE). Este manual, divulgado por organizações associadas às Nações Unidas, foi concebido com base em parâmetros estatísticos para as atividades de pesquisa e desenvolvimento e pretendeu instituir uma linguagem comum na discussão sobre políticas de ciência e tecnologia.

Os comitês assessores, compostos por cientistas reconhecidos e supostamente imunes a pressões de interesses regionais e/ou corporativos, ganharam autoridade para fazer a avaliação do mérito das demandas apresentadas ao CNPq. Foram também incumbidos de identificar as tendências da comunidade de pesquisadores, cada vez mais agitada pelo cerceamento da liberdade acadêmica e ampliada em decorrência do surgimento de numerosos programas de pós-graduação (DOMINGOS NETO, 2006). 
Entre as novidades arquitetadas pela hierarquia militar e as "missões" do Banco Mundial, destaca-se a criação da Empresa Brasileira de Pesquisa Agropecuária (Embrapa) (1973), responsável por promover a modernização agrária por meio de inovações tecnológicas, em cooperação com a Empresa Brasileira de Assistência Técnica e Extensão Rural (Embrater), que cumpriu importante papel na difusão de novos procedimentos para o trabalho agrícola. Parte integrante deste complexo, o Centro de Pesquisa Agropecuária do Trópico Semi-Árido (CPATSA) (hoje Embrapa SemiÁrido) foi fundado em 1975. O padrão agrícola moderno disseminado com o apoio financeiro e intelectual do BIRD dependia de um sistema de crédito subsidiado para acesso de produtores rurais a pacotes tecnológicos, da oferta de cursos de formação empresarial e cooperativismo, além da articulação com o setor produtivo (MARTINS, 2008).

Com incentivo do CNPq cresceram as pesquisas na área de engenharia rural e de tecnologia de alimentos, componentes essenciais de projetos direcionados para integração de grandes segmentos rurais, como o Programa de Integração Nacional-Programa de Redistribuição de Terras e de Estímulo à Agroindústria do Norte e Nordeste (PIN-Proterra), o Programa Especial de Apoio ao Desenvolvimento da Região Semi-Árida do Nordeste (Projeto Sertanejo) e o Programa de Áreas Integradas do Nordeste (Polonordeste), entre outros. ${ }^{13}$ Iniciado em 1975, o Proálcool recebeu empréstimos do Banco Mundial para pesquisa tecnológica e produção agroindustrial. ${ }^{14}$ Mas a expansão da cana-de-açúcar por vastas extensões em todo o território nacional exigia grandes investimentos em irrigação, variedades genéticas, mecanização e insumos químicos. O estímulo financeiro do Banco possibilitou contínua elevação dos padrões técnicos e da produtividade econômica. Desta forma, o setor agroindustrial brasileiro tornava-se competitivo internacionalmente.

Porém, o maior volume de recursos para ciência e tecnologia oriundos do Banco Mundial e do BID destinou-se ao financiamento de projetos

\footnotetext{
13 Enquanto o objetivo do Polonordeste (1974) era beneficiar os pequenos produtores rurais mediante atendimento das suas necessidades de produção, crédito, infraestrutura, associativismo, educação e saúde, o PIN-Proterra (1975) tinha como meta fomentar a agroindústria e redistribuir terras. O Projeto Sertanejo (1976) visava tornar o semiárido resistente a secas pela associação entre agricultura irrigada e de sequeiro. Nos três empreendimentos governamentais, a capitalização de empresas, via incentivos fiscais e outras modalidades de financiamentos, foi secundada por medidas de apoio à produção (tecnologia, assistência técnica, armazenamento e comercialização).
}

14 Alcohol and biomass energy development project. Report n. 3039-BR, 1981. Os recursos específicos para ciência e tecnologia foram aplicados pela FINEP e Secretaria de Tecnologia Industrial. 
de pesquisa do setor industrial e de adaptação de tecnologias importadas voltados, especificamente, para os ramos da mineração (titânio, magnésio, carvão, fósforo), eletrônica, alimentos, farmacêutico, siderurgia, informática e sistema de pesos e medidas. ${ }^{15}$ Provenientes do contrato de empréstimo CNPq/FINEP-BID, os recursos totalizaram 45 milhões de dólares, sendo a primeira parcela de 32 milhões liberada em 1973.

Dion Teles observou a atribulada convivência entre cientistas e militares no Conselho Científico e Tecnológico (CCT), órgão tripartite de caráter consultivo, mas ressaltou os "ganhos" advindos da postura "dinâmica" do CNPq: visibilidade em face da comunidade científica, implantação de núcleos integrados universidade-empresa, atuação na área de ciências humanas, abertura à inovação tecnológica e acesso da sociedade ao knowhow acumulado (MOTOYAMA, 2002). ${ }^{16}$

Distanciando-se desta visão, Waldimir Pirró e Longo afirmou em sua exposição no simpósio comemorativo dos 30 anos do CNPq (1981, p.32) que as tentativas de instituir um sistema de ciência e tecnologia aumentaram a dependência tecnológica do Brasil. ${ }^{17}$ Para Longo, ex-diretor da Fundação de Tecnologia Industrial, o "esforço magnífico" despendido pelo CNPq não conseguiu mobilizar a comunidade científica para participar na formulação dos grandes projetos nacionais e pouco repercutiu no setor produtivo, cada vez mais dominado por empresas estrangeiras.

Este era o caso, por exemplo, do setor elétrico, cujo avanço tecnológico foi dificultado por exigências do BIRD e do BID, que condicionavam a liberação de recursos para realização de empreendimentos à concorrência internacional. Tal procedimento beneficiava as corporações multinacionais em prejuízo dos países devedores, obrigados a importar produtos possíveis de ser supridos pela indústria local. Na década de 1960, a produção brasileira abastecia o mercado de equipamentos pesados para hidrelétricas; vinte anos depois, mais de 80\% destes equipamentos passariam a ser importados, sendo três quartos dos recursos provenientes dos próprios organismos multilaterais (PAYER, 1982).

15 PBDCT, 1973, p. 65-67.

16 O CCT era composto de 31 membros apontados pelo presidente da República, dos quais dezesseis representantes de instituições públicas e quinze representantes da comunidade científica, técnica e empresarial.

17 Longo é o primeiro coronel-engenheiro a ostentar a condição de PhD em Engenharia Militar no país. 


\section{A NEGOCIAÇÃO DO PROGRAMA DE APOIO AO DESENVOLVIMENTO CIENTÍFICO E TECNOLÓGICO}

As incertezas decorrentes da crise energética e da dívida externa tornaram o III PND (1980-1985) menos ambicioso do que os planos anteriores em suas pretensões de alcançar o "pleno desenvolvimento". Em 1984, o general João Baptista de Oliveira Figueiredo (1979-1984) assinou com o BIRD um acordo de empréstimo para aprimorar a competência técnico-científica nacional, mediante a elaboração do PADCT. Um ano depois, criou o Ministério da Ciência e Tecnologia (MCT), objeto de tentativas postergadas desde o final da década de 1950. De acordo com o então presidente do CNPq, Lynaldo Cavalcanti de Albuquerque (1980-1985), esta decisão provocou brusco esvaziamento de profissionais e funções do próprio órgão, no âmbito político (coordenação e planejamento), estratégico (ações de fomento) e operacional (execução da pesquisa pelos institutos). Na transição da ditadura para o Estado de direito, o Banco Mundial agiu no sentido de debilitar o CNPq, que deixou de ser a "cabeça" do sistema nacional de ciência e tecnologia, e ficou subordinado ao MCT (MOTOYAMA, 2002, p. 353).

$\mathrm{Na}$ avaliação do Banco Mundial, reproduzida em relatório do $\mathrm{CNPq}$ (1985) , haveria dificuldades na obtenção de estatísticas "confiáveis" e faltariam policy makers em ciência e tecnologia, em outras palavras, burocratas qualificados para planejar metas ditadas desde Washington, sem se preocupar com uma visão estratégica do país. Ademais, o CNPq se ressentiria de experiência para elaborar políticas em "situação de crise" e coordenar a atuação conjunta de órgãos públicos, empresas, universidades, instituições financeiras, poder legislativo, sociedades científicas e profissionais. As modalidades de fomento individual, oriundas de demanda espontânea, e a preocupação dos cientistas com a pesquisa básica eram apontadas como contrárias ao padrão da ciência moderna adotado pelo Banco Mundial. Foi, portanto, com o propósito de reorientar as ações programadas de pesquisa, enfatizando o conteúdo tecnológico e estreitando os laços da universidade com a estrutura produtiva privada, que o BIRD, em 1982, buscou entendimentos com o ministro Delfim Netto, da Seplan.

Esta orientação passou a condicionar o apoio dos organismos multilaterais ao desenvolvimento científico-tecnológico brasileiro e se estendeu aos acordos de cooperação bilateral firmados pelo Brasil com instituições estrangeiras dos países industrializados, entre estes, os de orientação socialista, como a então URSS (1981) e a China (1983). Ao CNPq competiria difundir o conceito de "inovação tecnológica" e implantar os 
mecanismos de articulação necessários para que a pesquisa acadêmica atendesse às demandas do setor produtivo. A estratégia de integração universidade-empresa envolveu, além da criação dos núcleos de inovação tecnológica, a organização de laboratórios associados e parques tecnológicos.

Neste período, o CNPq deu início a programas de caráter interdisciplinar e passou a vigorar uma nova tabela das áreas de conhecimento. Para atenuar "disparidades regionais", priorizaram-se os sistemas estaduais de ciência e tecnologia bem como as ações direcionadas às áreas "mais carentes". Coube ao BID financiar o Centro de Pesquisa de Produtos Florestais da Amazônia (1981) e o Programa de Desenvolvimento Científico e Tecnológico do Nordeste (1983). Cerca de 45 milhões de dólares destinados à geração e difusão de tecnologias apropriadas ao produtor de baixa renda possibilitaram o fortalecimento e a expansão de entidades de pesquisa, sobretudo acadêmicas (CNPq, 1985). Em conjunto, tais medidas levariam à "mudança de mentalidade" no CNPq, fator indispensável à implantação do PADCT.

Em 1983, o Banco Mundial comunicou ao CCT sua intenção de financiar um programa de ação com vistas a aprimorar as funções de coordenação, articulação e fomento das quatro agências integrantes do sistema nacional de ciência e tecnologia: CNPq, CAPES, FINEP e Secretaria de Tecnologia Industrial (STI). Caso fosse aceita sua proposta, a qual exigia a contratação de uma entidade externa para monitorar o programa (Grupo Especial de Acompanhamento), o Banco aportaria cerca de 100 milhões de dólares. Nos termos do secretário-executivo do PADCT, Waldimir Pirró e Longo:

Esse programa constitui, na realidade, o primeiro grande exercício de planejamento e ação de C\&T absolutamente coordenado pelo CCT. Ademais, esse programa muda a postura das agências, na medida em que elas lançarão os objetivos através de editais". ${ }^{18}$

A fala de Longo refletia um procedimento usual entre militares: planejar e executar decisões governamentais sem maior participação dos cientistas que o governo pretendia mobilizar. Estavam em jogo a estrutura e o funcionamento tanto do $\mathrm{CNPq}$ como de todo o sistema nacional de desenvolvimento científico e tecnológico.

18 Ata da $22^{\mathrm{a}}$ Reunião Ordinária do CCT, p.7. 
No decorrer do ano de 1984, os debates no Conselho se intensificaram, como revelam as atas das reuniões ordinárias. ${ }^{19}$ Na verdade, o programa em negociação entre o BIRD e a Seplan era levado ao CCT para uma consulta, "condicionada ainda a decisões superiores", comentou José Israel Vargas. Químico e ex-diretor do Instituto de Pesquisas Radioativas da UFMG, Vargas trabalhou no Centro de Estudos Nucleares de Grenoble, no período de 1966 a 1972, e exerceu o cargo de secretário de Ciência e Tecnologia de Minas Gerais. Eugenio Emílio Staub, formado em administração pela FGV e presidente da Gradiente, empresa do ramo de telecomunicações, se pronunciou de modo incisivo: o CNPq tinha planos, mas faltavam recursos; se o Banco Mundial estava disposto a fazer o empréstimo, "não há muito a discutir, basta apenas acatar". Já por sugestão do representante da CAPES, Edson Machado, era preciso aprovar a "intenção de elaborar um programa", sugestão apoiada pelo presidente do CNPq. Lynaldo Cavalcanti de Albuquerque esclareceu que o envolvimento do CCT, e não exclusivamente das quatro agências de ciência e tecnologia, devia-se à presença de uma missão do Banco Mundial e ao fato de tratar-se de um projeto interinstitucional. ${ }^{20}$

A ABC e a SBPC solicitaram ao CCT a suspensão do empréstimo do Banco Mundial e alguns conselheiros se manifestaram contrários ao PADCT. Expressando restrições à forma como o FMI vinha tratando o Brasil e às operações realizadas com o Banco Mundial, Crodowaldo Pavan, presidente da SBPC por três gestões consecutivas, discordou dos critérios de seleção das propostas e da remuneração dos consultores internacionais bem como da centralização do processo decisório. Pavan (1919-2009) destacou-se no campo da genética por seu trabalho no controle biológico de pragas da agricultura e foi o primeiro presidente do CNPq após a redemocratização do país, movimento no qual a SBPC esteve firmemente engajada.

Formado no Instituto de Tecnologia da Aeronáutica (ITA) e referência mundial em tecnologia de fibra ótica, José Ellis Ripper Filho reclamou das licitações internacionais praticadas pelo BIRD para aquisição de equipamentos, sobretudo de informática, pois contrariavam a política brasileira de informática, que estabelecia a reserva de merca-

19 As atas são das seguintes reuniões ordinárias do CCT: $21^{\mathrm{a}}(19 / 4 / 83), 22^{\mathrm{a}}(25 / 4 / 84), 23^{\mathrm{a}}$ $(19 / 12 / 84)$ e $24^{\mathrm{a}}(25 / 1 / 85)$.

20 Ata da $21^{\text {a }}$ Reunião Ordinária do CCT, p. 35-36. 
do. À época, na presidência da Fundação para o Desenvolvimento da Unicamp, Ripper sugeriu uma manifestação do Conselho repudiando qualquer empréstimo externo que ferisse a autonomia brasileira neste assunto. ${ }^{21}$

Afrânio Aragão Craveiro, no exercício do mandato de Pró-Reitor de Pesquisa e Pós-Graduação da Universidade Federal do Ceará (UFC) e com larga experiência na área de química orgânica, criticou a falta de considerações acerca da regionalização do desenvolvimento científico e tecnológico. Aliás, a defesa dos interesses regionais, juntamente com a interiorização das atividades do setor, constituía um traço característico da gestão de Lynaldo Cavalcanti de Albuquerque. ${ }^{22}$

Motivo de polêmicas e mal-entendidos entre os conselheiros, o ofício encaminhado pela diretoria da SBPC ao CNPq continha restrições ao PADCT. Destas, a principal se referia à parcialidade do julgamento dos projetos pelos membros dos comitês assessores, o que colocava em xeque a lisura da avaliação por pares. A SBPC reivindicava, ainda, o adiamento do edital sobre o referido programa até seu exame pelo presidente Geisel, que "detém a última palavra" em caso de divergência. Citado ofício retomava os termos de um documento da $A B C$ e SBPC propondo "maior participação da comunidade científica", que havia sido objeto de uma comissão especial designada para analisar a matéria. ${ }^{23}$ Enquanto as discussões prosseguiam no CCT, açuladas pela crescente contestação ao regime militar, a Comissão Transitória do PADCT começava a operar, especialmente ao definir critérios para priorizar áreas de conhecimento, estabelecer cronograma de análise de propostas, receber e aprovar projetos.

Concretizava-se, assim, a tendência do Banco Mundial de impor às agências de fomento que as deliberações, inclusive a divulgação dos objetivos do programa mediante editais, fossem tomadas ouvindo-se previamente os comitês assessores, os quais, para efeito, deveriam ser ampliados e reformulados, ganhando projeção nacional. Nesta contenda política, o Estado ficou na defensiva e, em derradeira instância, "cedeu poder" à comunidade científica. A partir de então, a avaliação por mérito foi entregue aos pesquisadores e consagrada plenamente como instrumento para indução das preferências acadêmicas.

21 Ata da 23a Reunião Ordinária do CCT, p. 5-7.

22 Ata da 24a Reunião Ordinária do CCT, p. 10.

23 Ata da 22a Reunião Ordinária do CCT, p. 7-8. 
Por entender serem as críticas lançadas sobre o PADCT, de fato, um questionamento à prática de avaliação do mérito por pares, que fundamentava a distribuição de benefícios públicos para a pesquisa científica pelas agencias de fomento, a maioria dos integrantes do CCT se posicionou em favor do contrato de empréstimo e de um documento produzido pelos comitês assessores. Elaborado sob a tutela dos técnicos do Banco Mundial, o documento "Contribuições para uma política de ciência e tecnologia" trazia quatro recomendações básicas:

1) reorganização do SNDCT com a criação de um ministério específico;

2) elevação em $2 \%$ do PNB para as atividades de pesquisa científica e tecnológica;

3) elaboração de um Plano Nacional de Ciência e Tecnologia;

4) apoio financeiro e fiscal às empresas privadas nacionais em atividades de pesquisa e desenvolvimento.

Para execução da primeira etapa do programa (1984-1989), o convênio CNPq-BIRD dispunha de 72 milhões de dólares de empréstimo e 163 milhões de dólares de contrapartida nacional. Exigência de praxe em financiamentos dos organismos multilaterais, a contrapartida atrelava parte da receita nacional, onerada com amortizações e juros, a propósitos estipulados pelo Banco Mundial. Os recursos do PADCT destinavamse à pesquisa científica em dez áreas "estratégicas ou carentes de maior impulso", a saber: biotecnologia, instrumentação, química, engenharia química, planejamento e gestão em ciência e tecnologia, manutenção, provimentos de insumos essenciais, tecnologia industrial básica, educação para a ciência e informação em ciência e tecnologia (CNPq, 1985, p. 56-57). Estas áreas correspondiam aos "pontos de estrangulamento" da indústria brasileira que requeriam prioridade nos investimentos públicos para aumentar sua competitividade. ${ }^{24}$

Tido como exemplo de planejamento "participativo e democrático", em virtude da presença de membros das sociedades empresariais e científicas, a elaboração do PADCT seguiu uma estratégia concebida de antemão pelo Banco Mundial: minimizar o papel do Estado nacional como formulador das políticas de desenvolvimento. Nisto foi favorecido pela exacerbação do sentimento antiestatal de parcelas da intelectualidade

24 Ainda hoje, estas áreas constituem "gargalos científicos" que afetam o setor industrial brasileiro, como se depreende do workshop "Ciência para um Brasil competitivo", realizado em maio de 2009, na sede da SBPC ("Jornal da Ciência", 12 de junho de 2009, p. 4). 
e da burguesia, após vinte e um anos de ditadura. Nos embates travados no âmbito do CCT, que acompanhavam a conjuntura de transição política no país, prevaleceram as definições do Banco Mundial acerca do desenvolvimento científico e tecnológico.

\section{CIÊNCIA PARA QUEM?}

Consoante é possível concluir, parte considerável do sistema de ciência e tecnologia ainda vigente decorreu das relações amistosas entre os governos militares e o Banco Mundial; ambos deixaram sua marca na produção de conhecimento no país. Essa proximidade teve origem em uma base doutrinária comum: o binômio "segurançadesenvolvimento" norteou as iniciativas modernizadoras tanto da corporação nacional quanto do organismo multilateral. No entanto, os oficiais brasileiros não mantiveram um alinhamento incondicional e, por vezes, divergiram das propostas do Banco Mundial, como revelam os embates em torno de projetos estratégicos para afirmar a soberania nacional.

A influência do Banco Mundial na gestão e financiamento da política científica, diferentemente da sua ingerência, por exemplo, nas políticas agrícolas ou educacionais, em que assumiu abertamente a posição de autoridade e árbitro das questões de desenvolvimento setorial, ocorreu de forma sutil. As diretrizes emanadas deste organismo multilateral, em consonância com o pensamento dos centros hegemônicos do capitalismo, fundamentavam-se na suposição de que a transferência de tecnologia dos países produtores aos receptores era algo "natural" e benéfico, uma etapa necessária na dinâmica do desenvolvimento.

Como procurei mostrar, as concepções e práticas disseminadas pelo Banco Mundial passaram a integrar a sistemática de planejamento do CNPq, agência concebida para amparar a autonomia nacional, e foram absorvidas pela comunidade acadêmica, zelosa da sua liberdade intelectual. Assim, à medida que se consolidavam no CNPq a estruturação da área de pesquisa científica e a avaliação por mérito das demandas acadêmicas, o Banco alargava consideravelmente seu papel intelectual junto às próprias instituições responsáveis pela produção de ciência e tecnologia: universidades, centros de pesquisa, laboratórios, empresas e associações científicas. Enquanto os pesquisadores reunidos nos comitês assessores do CNPq ganham proeminência em termos de definir as prioridades do setor, o Estado vê enfraquecida sua capacidade de indutor do desenvolvimento científico. 
Se a assistência técnica e financeira do Banco Mundial à política científica, por um lado, resultou na formação de maior número de doutores e em um sistema mais competitivo internacionalmente, por outro, pouco repercutiu no uso intensivo de inovações pelas empresas nacionais e aumentou a dependência tecnológica de grandes corporações e potências, além de contribuir para o endividamento externo do país. Em raras ocasiões se discutiu sobre a propriedade do conhecimento ou o domínio do mercado por tecnologias estrangeiras.

Ao concentrar os recursos destinados à pesquisa em regiões, áreas do conhecimento, instituições e pesquisadores, o sistema de ciência e tecnologia implantado pelos generais com apoio do Banco Mundial ampliou as desigualdades na sociedade brasileira, patrocinadora e beneficiária da produção do conhecimento. A produção científica e tecnológica persistiu inacessível à maioria dos brasileiros, não indo muito além dos muros das universidades e dos centros de pesquisa. Sem esforços no intuito de atenuar razoavelmente esta tendência e desenvolver competência nacional em ciência e tecnologia de modo a atender à diversidade social e regional do Brasil, como enfrentar os múltiplos desafios da pobreza, da construção da democracia e da inserção internacional do país?

\section{REFERÊNCIAS}

ANDRADE, A. M. R. de. Acordos e desavenças na política nuclear. In: DOMINGOS NETO, M. O militar e a ciência no Brasil. Rio de Janeiro: Gramma, 2010.

BANCO MUNDIAL. Informe sobre el desarrollo mundial, 1978. Washington: World Bank, 1978.

CARDOSO, M. L. Ideologia do desenvolvimento. Brasil: JK e JQ. 2. ed. Rio de Janeiro: Paz e Terra, 1978.

CASTRO, C.; D'ARAÚJO, M. C. Ernesto Geisel. Rio de Janeiro: Fundação Getúlio Vargas, 1997.

CERVO, A. L.; BUENO, C. História da política exterior do Brasil. 3. ed. Brasília: Editora UNB, 2008.

CNPq. Ciência e Tecnologia no Desenvolvimento Industrial. Anais do Simpósio comemorativo dos 30 anos do CNPq. São Paulo: Academia de Ciências do Estado de São Paulo, 1981.

Uma experiência de gestão em ciência e tecnologia. Brasília: SEPLAN/CNPq, 1985.

DOMINGOS NETO, M. Acerca da modernização do Exército. Comunicação e Política, v. 22, n. 3, set./dez. 2004. $\overline{\operatorname{dez} .2004}$

A trajetória do CNPq. Revista do Arquivo Nacional, v. 17, n. 2, jul./ 
Defesa e segurança como área do conhecimento científico. Tensões Mundiais, v.2, n. 3, jul./dez. 2006 (org.). O militar e a ciência no Brasil. Rio de Janeiro: Gramma, 2010.

FREIRE JUNIOR, O.; SANTANA, W. O interesse militar pelo laser: o caso Sérgio Porto. In: DOMINGOS NETO, M. (org.). O militar e a ciência no Brasil. Rio de Janeiro: Gramma, 2010.

GOEL, V. K. et al. Innovation systems: World Bank support of science and techonology development. World Bank: Washington, 2004.

GONOD, P. F. Clés pour le transfert technologique. Economic Developmente Institute, Washington D.C., World Bank, 1974

GONZALEZ, M.J. F. et al. O Brasil e o Banco Mundial: um diagnóstico das relações econômicas: 1949-1989. Brasília: IPEA, 1990.

HOLM-NIELSEN, L. et al. Institutional and Entrepreneurial Leadership in the Brazilian Science and Technology Sector: Setting a New Agenda. Washington: World Bank, 1996.

HUNTINGTON, S. Political order in changing society. New Harven, Yale University Press, 1969.

MARTINS, M. D. As políticas agrárias do Banco Mundial na América Latina. In: CARLEIAL NETO, Adelita (org.). Projetos nacionais e conflitos na América Latina. Fortaleza: Edições UFC, EdUECE, UNAM, 2006.

Guerra e desenvolvimento: as inflexões do Banco Mundial. Tensões Mundiais, v.3, n. 4, jan./jun. 2007, p. 56-95.

Açúcar no sertão: a ofensiva capitalista no Nordeste do Brasil. São Paulo: Annablume, 2008.

MARTINS, M.D.; FARIAS, F. O conceito de pobreza do Banco Mundial. Tensões Mundiais, v. 3, n. 5, jul./dez. 2007, p. 202-219.

MCNAMARA, R. A essência da segurança. Reflexões de um secretário da defesa dos Estados Unidos. São Paulo: Instituição Brasileira de Difusão Cultural, 1968.

MOTOYAMA, S. 50 anos de CNPq, contados por seus presidentes. São Paulo: FAPESP, 2002.

PAYER, C. The World Bank: a critical analysis. New York: Monthly Review Press, 1982.

SEPLAN. II Plano Nacional de Desenvolvimento Econômico (1975-1979). Brasília, dezembro de 1974.

. II Plano Básico de Desenvolvimento Científico e Tecnológico

(1975-1977). Brasília, março de 1976.

III Plano Nacional de Desenvolvimento Econômico (1980-1985).

Brasília, março de 1981.

SZMRECZÁNYI, T. O planejamento da agroindústria canavieira no Brasil.

São Paulo: Hucitec, 1979. 
O Banco Mundial e a política científica dos governos militares no Brasil

SCHWARTZMAN, S. (org.). Ciência e tecnologia no Brasil: uma nova política para um mundo global. São Paulo: FGV, 1993.

VIOLA, E. J.; LEIS, H. R. Desordem global da biosfera e nova ordem internacional: o papel organizador do ecologismo. Lua Nova. Revista de Cultura e Política, São Paulo/SP, n. 20, p. 145-178, 1990.

WORLD BANK. Alcohol and biomass energy development project. Report $n$. 3039-BR, 1981. 